\title{
Linguistic and Symbolic Elements in Luxury Fashion Advertising: A Qualitative Analysis
}

\author{
Cesare Amatulli ${ }^{1}$, Giovanni Pino $^{2}$, Manuela Iodice ${ }^{3} \&$ Robert Cascio $^{4}$ \\ ${ }^{1}$ University of Bari, Ionian Department of Law, Economics and Environment, Taranto, Italy \\ ${ }^{2}$ University of Salento, Department of Management, Economics, Mathematics, and Statistics, Lecce, Italy \\ ${ }^{3}$ LUISS University, Department of Business and Management, Rome, Italy \\ ${ }^{4}$ University of Central Florida, College of Business Administration, Orlando, Florida, USA \\ Correspondence: Cesare Amatulli, University of Bari, Ionian Department of Law, Economics and Environment \\ Via Lago Maggiore angolo Via Ancona, 74121, Taranto, Italy. E-mail: cesare.amatulli@uniba.it
}

Received: May 9, 2016

doi:10.5539/ijbm.v11n9p265
Accepted: July 27, 2016

Online Published: August 10, 2016

URL: http://dx.doi.org/10.5539/ijbm.v11n9p265

\begin{abstract}
This research investigates the use of English in luxury fashion print advertising, which continues to be the main channel to communicate new luxury fashion collections and products. The research aims to find cultural adaptations from the original Anglo-Saxon country to the target country. Further, this research examines the use of images in fashion magazines and, in particular, their capacity to deliver brand personality and aesthetics by creating a narrative engagement. By analyzing thirty print advertisements from U.S. and Spanish life-style magazines using the semiotic approach, checking for linguistic differences, and employing a robust, cross-cultural qualitative analysis, the authors conclude that each linguistic element in an advertisement may invoke an underlying message that can be comprehended by the majority of consumers, and that language selection itself can have a strong symbolic meaning.
\end{abstract}

Keywords: fashion marketing, foreign language, international advertising, linguistics, luxury brands, print advertising, semiotics, word choice

\section{Introduction}

The modern marketplace is characterized by the emergence of post-modern brands, which are brands that consumers associate more to symbolic and emotional features than to utilitarian aspects (Lee, 2009). In this new situation, luxury brands have changed the way to position and communicate themselves in the market, so that the "new" concept of luxury as opposed to traditional luxury now has more positive connotations and consumers buy luxury products for different reasons than the past. This new way to conceive the luxury sensation leads, however, to a paradox: on the one hand, luxury is a symbol of social eliteness and thus circumvents the masses; on the other, contemporary luxury is promoted by companies that remain bound to the logics of higher production volumes and distribution (Chevalier \& Mazzalovo, 2012). Thus, the optimal strategy for luxury marketing is to find a balance between the necessity to increase sales in order to achieve success in the marketplace, and the exclusivity that drives image and prestige pricing in hopes of maintaining or increasing its luxury character.

To increase the value delivered to the different segments of customers it is important for marketers and advertisers to understand the different reasons underlying the purchase of luxury goods (Wiedmann, Hennings, \& Siebels, 2007). In this regard, existing research suggests that the new luxury is based mainly on customers' experiences and feelings as long as luxury products are no longer a means of "social" distinction, but rather a means for "personal distinction": "new luxury goods are always based on emotions, and consumers have much more stronger emotional engagement with them than with other goods" (Silverstein, Fiske, \& Butman, 2003). The luxury purchase is influenced both by "internal" or "intrinsic" aims, for individual reasons, such as the search for satisfaction, hedonism, personal enjoyment, as well as for "external" or "extrinsic" aims, such as social recognition and external appreciation (Amatulli \& Guido, 2009). Therefore, while in the past, communication was just one element of the whole marketing plan, now it is the main tool to enlighten the multiple facets of a luxury brand. 
Even though the marketing landscape has significantly changed through the years (Nyilasy et al., 2011) and magazine and newspaper advertising has become a secondary medium for communication, for luxury companies, print advertising still represents a critically important media. Sashikala (2007), for example, found that print ads have the greatest impact on consumers' emotions after television. Print advertisements continue to be the main media to communicate new collections and products in the luxury fashion market. These advertisements convey a sense of sophistication and luxury through the right images and messages for this kind of market (Chevalier \& Mazzalovo, 2012).

Luxury fashion advertisements mostly consist of images, which sometimes completely replace text (Santaella, Summers, \& Belleau, 2012). This extensive use of images could lead one to believe that images trigger emotions in a more efficient and in a more persuasive way than text, perhaps because the ad is more memorable and recallable (Minard, et al., 1991). This is certainly plausible as we consider that images can deliver underlying messages that would be difficult to convey with text only, particularly cultural beauty and other aesthetic beliefs. However, existing research (Santaella, Summers, \& Belleau, 2012) suggests that both images and text in fashion advertising may be equally relevant, and the combination of visual and text elements is more effective than a text-only or image-only ad. Thus, even in the fashion market, it seems that consumers still look for some type of textual information.

This research investigates the role of the English as a main international language in luxury fashion advertising and seeks to understand whether any cultural adaptation to target country exists in luxury fashion advertising. The research also investigates the use of images in comparison to verbal descriptions in luxury fashion advertisements. In this respect, the research aims to understand whether luxury fashion brands prefer image-only ads over than text-only or image-and-text ads to deliver brand personality and aesthetics, impact on the viewer's emotional state and sense of involvement (Phillips \& Mcquarrie, 2010; Santaella, Summers, \& Belleau, 2012).

\section{The Role of English in Luxury Advertising}

In the modern globalized market, where companies operate internationally, language can become a major point in finding the way to communicate their critical marketing message. French is considered as symbol of refined taste and elegance, and German of technical reliability and precision. English is associated with modernity and practical lifestyle (Haarman, 1989) and it is dissociated with a country-of-origin stereotype, as it is a global language. English is indeed the lingua franca of international business (e.g., Graddol, 2000; Gerritsen et al., 2007; Ehrenreich, 2010). Furthermore, Krishna and Ahluwalia (2008) underscored that Indians who were fluent both in Hindi and English associated the use of English with sophistication and the use of Hindi with belongingness. They suggested that the use of local languages instead of English to convey prestige, quality, exclusivity, etc. is likely to fail, especially if used in the domain of luxury.

Previous research failed to provide significant evidence about the full comprehensibility of English by non-native speakers, giving way to a semiotic analysis of foreign words (Cerdeño, 2010; Haarman, 1989; Krishna \& Ahluwalia, 2008). Semiotics allows us to also understand how advertisers use English (or other foreign languages) to create meanings, cultural associations, and emotional bonds with the customer. Since there are not exhaustive semiotic studies on the use of English in luxury ads, this research focuses on this specific topic in order to fill an important gap in the luxury purchase and luxury consumer behaviour literature.

\section{Semiotics and Fashion Advertising}

Semiotics deciphers the "signs", mainly text and images, used to communicate a certain message to a given audience and assesses the effectiveness of communication (Bitoun, 2006). In the specific case of advertising, semiotics serves to decode hidden messages delivered to the viewers by assessing the interconnection between communication elements (Beasley \& Danesi, 2002). The first applications of semiotics to advertising by Barthes, in late 1960s, laid the ground to the development of the analytical tools of semiotic research and inspired subsequent works based on this approach. Semiotics allows one to decompose brand names, logos, packaging, and so on, at two different levels of interpretation: (1) a surface level one and (2) an underlying level one. The surface level regards the visible part of signs (words, images or colors) that lead to the underlying level, where the true meaning lies. At the underlying level, the association is most often linked to a mythical or archetypal world interacting with the subconscious mind of the consumer (Beasley \& Danesi, 2002). Semiotics is also used in advertising research to investigate unconscious desires and understand how activating and stimulating them increase propensity to purchase and overall consumer value. Indeed, fashion luxury brands rely on the emotional and sensory aspects to activate these desires. They evoke the "emotional" side of the consumption by using sensory associations. Consequently, everything in an ad - the background, the colors, the models' features and poses, and all the visible signifiers - can be analysed through semiotics. French semiotician Jean-Marie Floch's 
work (1995) conducted with popular luxury brands - namely, Chanel, Loewe, Ferragamo and Yves Saint-Laurent - has been the starting point for a semiotic analysis of the relationship between luxury, aesthetics and design. Bertrand (2002), who reviewed Floch's work, considered the semiotic approach of aesthetics as the very basis of luxury communication. This author underscored that luxury brand communication is based on an intimate relationship between the object and the person, emphasizing the frequent use of puns, myths, sensorial rhetoric embodying deeper meanings and emotions.

\section{Methodology}

\subsection{Selection of the Advertisements}

To investigate the use of English in luxury fashion advertising, we conducted a qualitative analysis of thirty ads printed in glossy, lifestyle magazines, in both the United States (U.S.) and Spain. The ads were provided by Visual $\mathrm{Box}^{\mathrm{TM}}$, a company leader in international fashion, beauty, design and lifestyle media-monitoring and analysis. We selected ads printed from fashion, life-style magazines in the U.S. and Spain during the 24-month period from January 1, 2011 to December 31, 2012. The U.S. and Spain are appropriate countries for our research as they share some basic belief systems in terms of religion, individualism, desire for power, and need for prestige, yet differ on other elements, such as health priorities, acceptable standards for professional / business / social attire, and level of formality in business and social settings. These similar and differing elements allow for important variability in the data collected in order to reach fundamental data conclusions discussed later in the paper. We conducted a cross-cultural analysis aimed at examining how English ads are adapted in the target country and, at the same time, investigating the role English has in print ads. We concentrated our research efforts on both the U.S. (the Anglophone country) and Spain. It is important to note that Spain is a country where English is recognized as international language and is compulsory in the Spanish scholar system. In addition, we selected this country because of the increasing use of English words in Spanish advertising which has taken place in the last two plus decades: 17\% in 1994 to 77\% in 2007 (Gerritsen et al., 2007). Secondly, we selected ads that were not influenced by other media. For the chosen campaigns, the print medium in glossy magazines was required to be one of the main tools for presenting the new collections in the luxury fashion sector. After a first download of forty campaigns, two for each brand, with one in a U.S. magazine and the other in a Spanish magazine, thirty campaigns, with a total of fifteen different brands, were selected. The brands chosen were: Bottega Veneta, Bulgari, Burberry, Chanel, Dior, Dolce \& Gabbana, Giorgio Armani, Gucci, Hermès, Louis Vuitton, Miu Miu, Prada, Salvatore Ferragamo, Tod's, and Valentino. These brands are highly recognized as those among the leaders in the luxury fashion market. All of these brands are Italian and French brands, except for the UK-based brand Burberry.

\subsection{Semiotic Analysis}

Each ad campaign was analysed under different points of view, focusing on both the format and the content. First, we considered the page size: is it oversized, standard, or small? Then, we considered the ad size relative to the size of the page. We also analyzed the positioning (placement) of the ad inside the magazine: was it the first, second, third or fourth cover?, the first half of the magazine?, or the second half of the magazine?. Then, we reviewed the eventual presence of text, specifically, the headline (the slogan), the body copy (the descriptive part of the ad which extends the headline), and the tagline (a short and highly memorable text). For each textual element, we counted the number of words and the number of English words and checked for possible linguistic differences between U.S. and Spanish ads. We also listed the number of individuals, the presence of celebrity endorsers in the ads, the number of objects, the logotype presence, and the packshot (the way products are presented in the ad). Finally, we examined the presence of rhetorical tropes both in the text and in the visual images (McQuarrie \& Mick, 1996). Given the prevalence of image-only ads, a visual rhetoric approach is applied in the qualitative analysis of each brand campaign. The use of visual rhetoric implies using images to create meanings, so that each element in the ad, such as models, celebrities, colors, products, camera angles, is examined in great depth to understand the complete intentions of the advertiser (Bulmer \& Buchanan-Oliver, 2006).

\section{Results}

Lack of textual information was a main characteristic found in the examined advertisements. In fact, the only ad with a headline was the one by Hermés; and in this case, the headline ("El tiempo contigo") did not include any English words. Ads with body-copy elements included Bulgari, Gucci, Louis Vuitton, and Miu Miu. In the case of Louis Vuitton, The body-copy elements were written in French in both the U.S. and Spanish ads, most likely to emphasize the French origin and heritage, which is a deep-rooted leitmotiv for luxury brands with high perceived value (Hennings et al., 2012). On the other hand, ads by the Italian brands Bulgari, Gucci, and Miu Miu, used English both for U.S. and Spanish advertisements despite their origins. In a Gucci ad, for instance, the body-copy "Shop the digital flagship store Gucci.com" is an invitation to visit the online store of this brand. English was most 
likely chosen to allow the reader to clearly understand what is written and what is being asked of the international consumer. Moreover, the choice of English could be also associated with the innovativeness of e-commerce sites, where the Internet can be considered almost entirely the domain of English (Graddol, 2000). The body-copy in the ads refers to the place and day of the shooting and celebrity's and photographer's names. The choice of language may not seem so relevant as there are just two words in both the body-copy and they are in English. No translations from English were ascertained, except for the afore-mentioned Hermès campaign, were the English headline "Time on your side" was translated in the Spanish "El tiempo contigo", respecting its exact meanings. The absence of text in every other campaign implies that visual imagery plays the key role in delivering the ad message for luxury fashion brands.

\subsection{Themes Emerged from the Semiotic Analysis}

Semiotics was employed to obtain a meaningful interpretation of the visual elements of the examined print ads. This analysis revealed that through the use of a rhetoric language, lifestyle elements were transferred to the product and the brand. Products had no mention of functionality in the ads, but rather they belonged to an imagined, exclusive and unique world that can be accessed by owning the product (the luxury "dream"). Indeed, the semiotic analysis reported a large use of metaphors, through which powerful emotions are evoked by the images and are then transferred to the advertised products, making them more memorable and desirable (Miniard et al., 1991). The following six themes emerged from the semiotic analysis:

1. Myths. Luxury brands use myths, cultural icons, and artwork to deliver their aesthetic visions. In the Bulgari's Spanish campaign, the process of mythologization is evident: a sensual woman, dressed only in jewelry, and caressing a lion represents a modern Eve in the Eden garden. The woman symbolizes timeless beauty, seduction and femininity. The lion (the "king" of the animals) symbolizes majesty. All these meanings are transferred to the advertised product, a handbag, which covers the model's body while she caresses the lion with the other hand, almost creating a metaphoric connection between the lion and the handbag.

2. Cultural icons. The Miu Miu's campaign contained clear references to the historical figure of the French Queen Marie Antoinette, because of the hairstyle and the vintage clothing and jewelry depicted in the ad. The Queen was an icon of beauty and style and had a strong influence in French fashion. However, the idea of classicism delivered by the Queen is contrasted by the image of a young woman holding a bag and the juxtaposition of two vivid colors, yellow and pink. The interplay of "old" and "new" is part of the identity of the Miu Miu brand which proposes itself as a modern and young brand, evoking the past, but with an eye to the future. The Bulgari's campaign is also characterized by cultural references. It features an old portrait of the famous actress Isabella Rossellini playing the role of a seducing woman that wears a black dress with one shoulder strap down as in David Lynch's movie "Blue Velvet". The campaign also refers to the work of the English painter Meredith Frampton, which taps into her classic neo-realism. Both cultural references strengthen the concept of ageless beauty and immortality that the brand sees value in invoking.

3. Timeless dimensions. Most of the campaigns create a suspended moment in time and contradictions between different temporal modes were represented. The ads mixed present and past, tradition and modernity, fads and persistence, and emphasized the immortality of the brand. Referencing Valentino's U.S. campaign, there is a woman, almost entirely in the dark in a very tenous atmosphere, and it is difficult to see her whole dress. Moreover, the woman is looking outside the ad border in an intense pose, sitting on a chair like she is waiting for someone or something to happen. Time is clearly suspended and this reflects a typically used characteristic of luxury brands as they have to maintain their identity over time, yet remain in step with fashion and fads (Kapferer \& Bastien, 2009).

4. The sense of lack. Some of the advertisements examined in the research were aimed to communicate a sense of lack and the search for the fulfilment of a desire (Bertrand, 2002). In the case of Valentino's campaign, the advertiser is attempting to deliver a mysterious message that and the viewer is not able to fully understand what is going on. A similar atmosphere is created by Dior in an ad featuring a woman in a car, which is only partially visible. The viewer catches only a split-second image before the car goes away. The atmosphere is dark and dreamy, again introducing mystery as well as drama. We cannot know where the woman is going, but clearly it invokes a viewer's imagination to run wild. These absences of finality enhance the theme of lack, which is metaphorically the lack of the luxurious bag, the Dior dream in the viewer's life.

5. Narrative involvement. In other cases, it is possible to recognize a sort of "plot". In the Dolce \& Gabbana's campaign in the U.S. magazine, for instance, the viewers easily identify the portrayed location: a Sicilian town where people wear the traditional "coppola" hat. The ad features characters in a convivial situation, probably after the Sunday Mass / Church. Other elements, namely, the baroque style of clothes and accessories and characters' gestures function as metaphoric elements that strengthen the Italian origin and heritage of the brand. Similarly, in 
the Louis Vuitton ad, the plot serves to deliver this brand's heritage. The examined ad features a woman on a hot-air balloon looking somewhere outside the ad border, as toward an unknown destination and her future. This image recalls a recurrent theme in Louis Vuitton's campaigns: "travel" (Vuitton initially produced trunks). In this ad, visual elements completely replace text as means of communication of brand identity, aesthetic vision and luxury dream.

6. Heritage. Every luxury fashion brand is characterized by a distinctive stylistic code based on signs, colours, materials that create a visual identity. The code is the signature of the brand aesthetic over all the collections and a unique representation of its idealized woman or man. Thus, the more the products are part of a symbolic and cultural world that can be associated to the brand identity, the more the non-verbal communication has a strategic function in the communication program. Prada's androgynous models are portrayed in a futuristic world, symbolizing the modern and innovative stylistic approach of this brand. In the Chanel campaign in the U.S., the contrast between the androgynous and masculine-looking model and the feminine and refined clothes and furniture become a metaphor of the dualism embodied in the Chanel aesthetic vision and values prized by the company. Indeed, the Chanel's woman is characterized by an androgynous charm, as a statement of independence in itself, but also by femininity and refined style. The half-shaved head, the tattoos and the ripped tights depicted in the Chanel campaign are elements connected with the punk culture in which its main values are the rejection of social or behaviour control and a strong passion for individual freedom. Through these visual elements, the campaign, and therefore the brand, taps into this culture and endorses its values to represent the Chanel's idealized representation of a woman.

\section{Discussion and Implications}

The study highlighted the absence of text elements in virtually every ad and the predominance of visual elements beneath which the underlying messages of the campaign were held. Results show that the absence of text in almost every campaign implies that visual imagery plays a more heightened role in delivering the ad message for luxury fashion brands. Further, this suggests that a communication based on "silence" rather than text, is more effective for positioning lifestyle luxury products. The absence of textual information enables us to tentatively conclude that image-based, silent print ads achieve the advertiser's intended objective in a more effective manner than those with substantial text. The absence of text also implies that luxury fashion campaigns are complex, deep, and thought provoking and thus difficult to put into words. No significant differences between the U.S. and Spanish ads emerged from our analysis as only in one case a headline was translated in Spain, whereas in the other cases the text was written in English for both the U.S. and the Spanish ads.

Through the semiotic analysis, the study detected a wide use of visual rhetoric, metaphors, particularly inspired by myths and icons of culture, to deliver luxury aesthetic visions. These metaphors embedded deeper processing of messages and helped communicating sensory and aesthetic information that reinforced advertising claims: luxury consumption, in its hedonic facets, and the important association to multi-sensory and emotive aspects of the consumer experience (Chang \& Yen, 2013). The luxury fashion brands communicate on the terms of style and visual identity. Consequently, the luxury fashion brands need semiotic "grammar" in order to express themselves coherently with their own stylistic identities. The introduction of myths, timeless dimensions, narrative scenes, and sensory experiences transfers the underlying meanings and symbols from the pictorial elements to the advertised product and its brand. In this way, images create an on-going multimodal dialogue between the brand and the consumer. Such a dialogue contains implicit messages and sophisticated rhetorical meanings communicated through the manner in which the object is represented, the position of the models' body, the camera point of view, the colours of the ad, and so on.

The implementation of a semiotic approach in luxury advertising, where emotions are the core of communication, may help marketing managers to build significant symbols and metaphors through images. Semiotics might support the creation of meanings that are able to speak to the unconscious mind of the consumer. Indeed, as sensorial feelings and desires traditionally associated with luxury goods can be difficult or even impossible to be described through words, images can be more easily constructed with multiple levels of meanings. Our results suggest that marketing managers should design and pilot test campaigns by selecting effective pictures and visual rhetoric allowing them to avoid costly mistakes as the potential for unknown and unintended interpretation is plausible and costly to the brand value. In this respect, the approach adopted in this research could serve as a guide for marketing managers and help them increase the coherence between the semiotic structure of luxury fashion ads and the values of the advertised brands.

\section{Limitations and Future Research}

This research examined thirty luxury fashion advertisements. We believe the intensive semiotic analysis of 
multiple elements of each ad to be internally and externally valid and reliable given this research methodology and sample size. In semiotic analysis, smaller sample sizes are the norm (Langrehr \& Caywood, 1995), so we are in line with previous research. That said, provided time and expense become less restrictive, the ability to analyse more ads of this type could prove fruitful. Aside from this limitation, this study has offered substantial contributions which can lead to further and deeper research on luxury fashion advertising. Further research could include, in particular, a quantitative study to further demonstrate the actual predominance of only images rather than the use of images and text in print ads. Also, verifying the prevalence of English in non-Anglo-Saxon countries in this quantitative study would be helpful. Future research could also assess whether the use of visual rhetoric, narrative transportation and symbolic codes in delivering luxury messages could increase the consumer's engagement with the brand. This would be a welcomed addition to the literature. Finally, future studies could seek to understand whether and how well the messages hidden in print advertisements are understood and interpreted by customers that have different cultures.

\section{References}

Amatulli, C., \& Guido, G. (2012). Externalised vs. Internalised Consumption of Luxury Goods: Propositions and Implications for Luxury Retail Marketing. The International Review of Retail, Distribution and Consumer Research, 22(2), 189-217. http://dx.doi.org/10.1080/09593969.2011.652647

Barthes, R. (1968). Elements of Semiology. New York: Hill \& Wang.

Barthes, R. (1977). The Rhetoric of the Image. In R. Barthes (Ed.), Image Music, Text. London: Fontana (Original French version 1972).

Beasley, R., \& Danesi, M. (2002). Persuasive Signs. The Semiotics of Advertising. Berlin, New York: Mouton de Gruyter.

Bertrand, D. (2002). Approche Sémiotique du Luxe: Entre Esthétique et Esthésie. Revue Française du Marketing, 187, 73-82. http://dx.doi.org/10.1515/9783110888003

Bitoun, C. (2006). Semiotics, as a Tool to Understand and Take Actions. Marketing Review, 6(2), 111-121. http://dx.doi.org/10.1362/146934706777977538

Bulmer, S., \& Buchanan-Oliver, M. (2006). Visual Rhetoric and Global Advertising Imagery. Journal of Marketing Communications, 12(1), 49-61. http://dx.doi.org/10.1080/13527260500289142

Cerdeño Gomez, T. (2010). The Use of Foreign Words as a Persuasive Tool in Marketing Discourse: The Cultural Stereotype of Global English in Spanish Print Advertising, E-prints Complutence. Website Temoa: Open Educational Resources (OER). htttp://www.temoa.info/node/678444

Chang, C. T., \& Yen, C. T. (2013). Missing Ingredients in Metaphor Advertising: The Right Formula of Metaphor Type, Product Type, and Need for Cognition. Journal of Advertising, 42(1), 80-94. http://dx.doi.org/10.1080/00913367.2012.749090

Chevalier, M., \& Mazzalovo, G. (2012). Luxury Brand Management. New York: Wiley.

Ehrenreich, S. (2010), English as a Business Lingua Franca in a German Multinational Corporation. Journal of Business Communication, 47(4), 408-431. http://dx.doi.org/10.1177/0021943610377303

Floch, J. M. (1995). Identités visuelles. Paris, Puf.

Gerritsen, M., Nickerson, C., Brandt, C. V. D., Crijns, R. M. J., Domínguez Rodríguez, N., Meurs, F. V., \& Nederstigt, U. (2007). English in Print Advertising in Germany, Spain and the Netherlands: Frequency of Occurrence, Comprehensibility and the Effect on Corporate Image, In G. Garzone \& C. Illie (Eds.), The role of English in institutional and business settings: An intercultural perspective (pp. 79-98). Berlin: Peter Lang.

Graddol, D. (2000). The Future of English. UK: The British Council.

Haarman, H. (1989). Symbolic Value of Foreign Language Use: From the Japanese Case to a General Sociolinguistic Perspective, Berlin: Moutoun de Gruyter. http://dx.doi.org/10.1515/9783110868395

Hennings, N., Schmidt, S., Wuestefeld, T., \& Wiedman, K. P. (2012). Brand Heritage in the Luxury Industry: Creating and Delivering Continuous Value to Consumers. AMA Summer Educator's Conference Proceedings, 23, 129-130.

Kapferer, J. N., \& Bastien, V. (2009). The Luxury Strategy: Break the Rules of Marketing to Build Luxury Brands, London and Philadelphia: Kogan Page.

Krishna, A., \& Ahluwalia, R. (2008). Language Choice in Advertising to Bilinguals: Asymmetric Effects for 
Multilingual Communication. Journal of Consumer Research, 35(4), 692-705. http://dx.doi.org/10.1086/592130

Langrehr, F. W., \& Caywood, C. (1995). A Semiotic Approach to Determining the Sins and Virtues Portrayed in Advertising. Journal of Current Issues and Research in Advertising, 17(1), 33-47. http://dx.doi.org/10.1080/10641734.1995.10505024

Lee, E. J. (2009). Theoretical Foundation of Brand Personality for Postmodern Branding Dynamics: A Critical Review and Research Agenda. Advances in Consumer Research, 36, 886-888. http://acrwebsite.org/volumes/14678/volumes/v36/NA-36

Levy, S. J. (1981). Interpreting Consumer Mythology: A Structural Approach to Consumer Behavior. Journal of Marketing, 45(3), 49-61. http://dx.doi.org/10.2307/1251541

McQuarrie, E. F., \& Mick, D. G. (1996). Figures of Rhetoric in Advertising Language. Journal of Consumer Research, 22(4), 424-438. http://dx.doi.org/10.1086/209459

Minard, P. W., Bathia, S., Lord, K. R., Dickson, P. R., \& Unnava, H. R. (1991). Picture-based Persuasion Processes and the Moderating Role of Involvement. Journal of Consumer Research, 18(1), 92-107. http://dx.doi.org/10.1086/209244

Nyilasy, G., Whitehill K., K., Reid, L. N., \& McDonald, S. C. (2011). Checking the Pulse of Print Media. Journal of Advertising Research, 51(1), 177-175. http://dx.doi.org/10.2501/JAR-51-1-167-181

Phillips, B. J., \& Mcquarrie, E. F. (2010). Narrative and Persuasion in Fashion Advertising. Journal of Consumer Research, 37(3), 368-392. http://dx.doi.org/10.1086/653087

Santaella, M., Summers, T., \& Belleau, D. (2012). Involvement in Fashion Advertising: The Role of Images. Academy of Business Journal, 2, 66-67.

Sashikala, P. (2007). Emotional Intelligence and effectiveness of Advertising. ICFAI Journal of Consumer Behavior, 2(4), 48-58.

Silverstein, M. J., Fiske, N., \& Butman, J. (2003). Trading Up: Why Consumers Want New Luxury Goods and How Companies Create Them. New York: Penguin Group.

Wiedmann, K. P., Hennings, N., \& Siebels, A. (2007). Measuring Consumers' Luxury Value Perception: A Cross-Cultural Framework. Academy of Marketing Science, 7(7), 333-361.

\section{Copyrights}

Copyright for this article is retained by the author(s), with first publication rights granted to the journal.

This is an open-access article distributed under the terms and conditions of the Creative Commons Attribution license (http://creativecommons.org/licenses/by/4.0/). 